\title{
Weight Perception, Weight Control Intentions, and Dietary Intakes among Adolescents Ages 10-15 Years in the United States
}

\author{
Andrea L. Deierlein ${ }^{1, *}$, Alomi Malkan ${ }^{1}$, Jaqueline Litvak ${ }^{1}$ and Niyati Parekh ${ }^{1,2}$ \\ 1 College of Global Public Health, New York University, New York, NY 10003, USA; am8140@nyu.edu (A.M.); \\ j17598@nyu.edu (J.L.); np31@nyu.edu (N.P.) \\ 2 Department of Population Health, School of Medicine, New York University, New York, NY 10016, USA \\ * Correspondence: ald8@nyu.edu; Tel.: +1-212-992-5639
}

Received: 5 February 2019; Accepted: 15 March 2019; Published: 19 March 2019

check for updates

\begin{abstract}
Background: To examine associations of adolescents' weight status perception and weight control intentions with dietary intakes. Methods: Cross-sectional data from adolescents aged 10-15 in the National Health and Nutrition Examination Surveys, 2005-2014 ( $\mathrm{n}=4940)$. Adolescents responded to questions regarding weight perception and if they were trying to change their weight. Intakes of calories, protein, carbohydrate, fat, saturated fat, sugar, and fiber were assessed using 24-h dietary recalls. Multivariable linear regression estimated associations of intakes with weight perception and weight control intentions. Results: The majority of adolescents perceived their weight as "about right"; however, $45 \%$ and $46 \%$ of boys and girls, respectively, reported trying to change their weight. Weight perception was not associated with intakes, with the exception of lower sugar $(-13.65 \mathrm{~g}, 95 \% \mathrm{CI}:-23.06,-4.23)$ and higher percent calories from protein $(1.01 \%, 95 \% \mathrm{CI}: 0.16,1.87)$ in boys with overweight/obesity who perceived themselves as overweight, as well as lower percent calories from saturated fat $(-1.04 \%, 95 \%$ CI: $-2.24,-0.17)$ among girls with normal weight who perceived themselves as overweight. Weight control intentions were associated with intakes in boys only. Compared to boys who never tried to lose weight, boys who tried to lose weight consumed fewer calories $(-188.34 \mathrm{kcal}, 95 \% \mathrm{CI}:-357.67,-19.01)$, a lower percent of calories from fat $(-1.41 \%$, $95 \% \mathrm{CI}:-2.80,-0.02)$, and a greater percent of calories from protein $(1.48 \%, 95 \% \mathrm{CI}: 0.41,2.55)$. Conclusions: Despite perceiving weight as "about right", many adolescents reported trying to change their weight, which was associated with some dietary intakes. Efforts may be necessary to educate adolescents on healthy nutrition and weight management behaviors.
\end{abstract}

Keywords: adolescent; weight; perception; diet; weight management; behaviors

\section{Introduction}

Misperception of weight status, defined as under- or overestimating actual weight, is prevalent among adolescents in the United States (U.S.) [1,2]; approximately 30\% of 8-15 year olds misperceive their weight status [2]. Characteristics associated with misperception of weight status in adolescents include their body mass index (BMI, $\mathrm{kg} / \mathrm{m}^{2}$ ), gender, and race/ethnicity [2-6]. Although prevalence estimates vary by population, in general, adolescents with overweight or obesity tend to underestimate their weight, while those with normal weight may overestimate it $[3,5,6]$. Female adolescents are more likely than males to overestimate their weight status [4], while white adolescents are more likely to overestimate their weight status compared to their non-white counterparts [4,5]. Perception of weight status, independent of BMI status, is associated with poor weight management practices, including skipping breakfast and fasting, which may contribute to weight gain and the development 
of obesity [4,7-12]. It may also influence intakes of nutrients necessary for optimal growth and development [5,13-16].

Evidence from studies that investigate associations of adolescents' weight status perception and diet (assessed as food groups, calories, and/or macro- and micronutrients) is inconsistent. In studies of adolescents ages 12 years and older, weight status perception was not related to intakes of low nutrient-dense foods (e.g., percent of calories from sweets and salty snacks), macronutrients (e.g., percent of calories from carbohydrates), or micronutrients (e.g., B vitamins, calcium, iron) [13,14]. However, among participants in the China National Health and Nutrition Survey (2004-2009), perception of being overweight was associated with higher calorie, fat, and protein intakes in 6-11 year olds but was not associated with intakes in 12-17 year olds [15]. Additionally, among a nationally representative sample of eighth grade students, those who underestimated their weight reported buying junk food and fast foods at school more frequently than those who accurately perceived their weights, although no statistically significant differences in reported consumption of soda, fruits, or vegetables were observed [5].

The possible influence of adolescents' weight status perception on their nutrient intakes remains understudied in the literature, particularly among populations that are ethnically diverse and include adolescents of younger ages (prior to entering high school). In the current study, we examined associations of weight status perception, weight control intentions (e.g., desire to lose or gain weight), and nutrient intakes utilizing recently collected data (2005-2014) from a large, U.S. nationally representative sample of adolescents aged $10-15$ years.

\section{Methods}

Data came from the National Health and Nutrition Examination Surveys (NHANES), 2005-2014. NHANES is a program of studies conducted by the National Center for Health Statistics designed to assess the health and nutrition status of non-institutionalized children and adults in the U.S. using a nationally representative sample. It consists of three components: an in-person interview, which includes collection of sociodemographic, dietary, and health-related information; a physical examination; and laboratory analyses [17]. Informed consent (oral assent and parental permission for children < 12 years; informed assent for children ages 12-17 years) was obtained from all participants, and approval for the studies was obtained from the National Center for Health Statistics' Research Ethics Review Board [18]. Information on NHANES and all procedures are extensively detailed elsewhere [19]. The current study was exempted from the human subjects review by the New York University Institutional Review Board.

Questions on weight status perception were added to the NHANES protocol beginning in 2005 and were only administered to children and adolescents ages 8-15 years. There were 7297 children and adolescents with information on weight status perception (2005-2014). Children who were 8-9 years old $(n=1869)$ were excluded from these analyses to focus on adolescents. Additionally, adolescents who were missing measured BMI $(n=32)$, underweight $(B M I<5$ th percentile, $n=171)$, missing dietary data $(n=251)$, or reported implausible energy intakes (e.g., likely not reflective of habitual intakes, $<500 \mathrm{kcals} /$ day, $\mathrm{n}=18$ or $>5000 \mathrm{kcals} /$ day, $\mathrm{n}=16$ ) were excluded. The final sample consisted of 4940 adolescents aged 10-15 years. Information on sociodemographic characteristics including gender, age, race/ethnicity (non-Hispanic white, non-Hispanic Black, Hispanic, or Other), and household income, defined by the poverty-to-income ratio (PIR) and categorized as low $(<130 \%)$, medium $(130 \leq 350 \%)$, or high $(\geq 50 \%)$, were collected during the in-person interview.

\subsection{Measured and Perceived Weight Status and Weight Control Intentions}

Height (nearest 0.001 meter, $\mathrm{m}$ ) and weight (nearest 0.1 kilogram, $\mathrm{kg}$ ) were measured by trained healthcare professionals as part of the NHANES physical examination and used to calculate BMI $\left(\mathrm{kg} / \mathrm{m}^{2}\right)$ and BMI percentiles $[17,19]$. Measured weight status was categorized as normal weight (5th $\leq 85$ th BMI percentile), overweight (85th $\leq 95$ th BMI percentile), or obese ( $\geq 95$ th BMI percentile) 
according to the Centers for Disease Control and Prevention growth charts [20]. Weight status perception was assessed using responses to the question 'How do you consider your weight?' (fat or overweight, too thin, or about the right weight). Weight control intentions were assessed using the responses to two questions: (1) 'Are you trying to do anything about your weight' (lose weight, gain weight, or stay the same weight/do nothing about weight) and (2) 'In the past year, how often have you tried to lose weight?' (never, sometimes, or a lot).

\subsection{Dietary Intakes}

Adolescents completed up to two 24-h dietary recalls. The first recall was collected in-person and the second recall was collected over the phone 3-10 days later. For adolescents aged 10-11 years, dietary recalls were completed with a parent/caregiver present in the room, while those aged 12 years and older completed the recalls alone. Approximately $90 \%$ of adolescents $(n=4466)$ completed both dietary recalls, and intakes from these recalls were averaged. Reported intakes of calories, percent of calories from protein, percent of calories from carbohydrate, percent of calories from fat, percent of calories from saturated fat, grams of sugar, and grams of fiber were considered in analyses.

\subsection{Statistical Analysis}

Stata version 15.1 (College Station, TX, USA) was used for all analyses. Bivariate associations between weight status perception and sociodemographic characteristics were tested using Pearson's chi-square test or linear regression (for continuous variables). Multivariable linear regression was used to estimate associations of dietary intake variables with weight status perception and weight control intentions. All models were stratified by gender and adjusted for race, continuous age, BMI percentile, and PIR. Models for weight status perception were stratified by BMI status (dichotomized as normal weight and overweight/obese); though formal tests of statistical interaction were not significant $(p>0.05)$. Models for grams of sugar and fiber were also adjusted for total calories. All analyses were statistically weighted as required for the complex survey design of NHANES.

\section{Results}

The majority of adolescents were white, from households with a medium or high PIR, and normal weight; there were no differences in the distributions of these characteristics between boys and girls, as shown in Table 1. The mean (standard error, SE) for age and BMI percentile were $12.5(0.05)$ years and $69.4(0.01) \%$ among boys and $12.5(0.05)$ years and $70.5(0.01) \%$ among girls. Distributions of weight status perception and weight control intentions varied by measured weight status (BMI percentile categories: normal, overweight, or obese) and are provided in Table 2. The majority of boys and girls with normal weight or overweight perceived their weight as about right, while only $43 \%$ of boys and $31 \%$ of girls with obesity perceived their weight as about right. Weight control intentions, especially to lose weight, were prevalent (Table 2). Among boys with normal weight, overweight, or obesity, 25\%, $65 \%$, and $85 \%$, respectively, reported trying to lose weight during the previous year, while among girls, $42 \%, 71 \%$, and $92 \%$, respectively, reported trying to lose weight in the previous year.

Associations of weight status perception and weight control intentions with dietary intakes among boys and girls are shown in Tables 3 and 4, respectively. Among boys with overweight and obesity, those who perceived themselves as overweight reported consuming less sugar $(-13.65 \mathrm{~g}, 95 \% \mathrm{CI}$ : $-23.06,-4.23)$ and more calories from protein $(1.01 \%, 95 \%$ CI: $0.16,1.87)$, compared to those who perceived themselves as just right. Among girls with normal weight, those who perceived themselves as overweight reported consuming less calories from saturated fat $(-1.04 \%, 95 \%$ CI: $-2.24,-0.17)$ compared to those who perceived themselves as just right. 
Table 1. Distributions of selected characteristics of adolescents ages 10-15 years, stratified by gender, participating in the National Health and Nutrition Examination Survey NHANES 2005-2014 $(n=4940)$.

\begin{tabular}{|c|c|c|c|}
\hline \multirow{3}{*}{ Characteristic } & Boys & Girls & \multirow{3}{*}{$p$-Value ${ }^{\text {a }}$} \\
\hline & $n=2493$ & $n=2447$ & \\
\hline & $\%$ & $\%$ & \\
\hline Race/Ethnicity & & & 0.41 \\
\hline Non-Hispanic White & 58 & 58 & \\
\hline Non-Hispanic Black & 13 & 15 & \\
\hline Mexican & 14 & 15 & \\
\hline Other & 14 & 13 & \\
\hline Household Poverty Income Ratio & & & 0.18 \\
\hline Low $(<130 \%)$ & 27 & 31 & \\
\hline Medium (130-349\%) & 36 & 35 & \\
\hline $\operatorname{High}(>=350 \%)$ & 37 & 34 & \\
\hline \multicolumn{4}{|l|}{ Measured WeightBMI Status } \\
\hline Normal Weight (5th-85th percentile) & 59 & 59 & 0.99 \\
\hline Overweight (85th $\leq 95$ th percentile) & 19 & 19 & \\
\hline \multirow[t]{2}{*}{ Obese $(\geq 95$ th percentile) } & 22 & 22 & \\
\hline & Mean (SE) & Mean (SE) & $p$-Value ${ }^{\mathrm{b}}$ \\
\hline \multicolumn{4}{|l|}{ Daily Dietary Intakes } \\
\hline Calories, Kilocalories & $2191.61(26.65)$ & $1803.5(18.3)$ & $<0.001$ \\
\hline Percent Calories from Carbohydrates, $\%$ & $53.0(0.27)$ & $53.2(0.27)$ & 0.45 \\
\hline Percent Calories from Fat, \% & $33.0(0.22)$ & $33.3(0.20)$ & 0.16 \\
\hline Percent Calories from Saturated Fat, \% & $11.6(0.08)$ & $11.4(0.09)$ & 0.10 \\
\hline Percent Calories from Protein, $\%$ & $15.1(0.10)$ & $14.6(0.14)$ & 0.004 \\
\hline Sugar, in grams & $138.5(2.7)$ & $111.8(1.5)$ & $<0.001$ \\
\hline Fiber, in grams & $14.9(0.24)$ & $12.9(0.16)$ & $<0.001$ \\
\hline
\end{tabular}

NOTE: ${ }^{\mathrm{a}} p$ value from chi square test; ${ }^{\mathrm{b}} p$ value from linear regression.

Table 2. Distributions of weight status perception and weight control intentions, stratified by measured weight status (normal, overweight, or obese) and gender, among adolescents participating in the National Health and Nutrition Examination Survey 2005-2014 $(n=4940)^{\text {a }}$.

\begin{tabular}{|c|c|c|c|c|}
\hline \multirow{3}{*}{ Categories } & \multicolumn{4}{|c|}{ Measured Weight Status } \\
\hline & All & Normal & Overweight & Obese \\
\hline & $\%$ & $\%$ & $\%$ & $\% b$ \\
\hline \multicolumn{5}{|l|}{ Boys } \\
\hline \multicolumn{5}{|l|}{ Weight Status Perception } \\
\hline About Right & 76 & 87 & 80 & 43 \\
\hline Too Thin & 7 & 12 & 0.4 & 1 \\
\hline Overweight & 17 & 1 & 19 & 56 \\
\hline \multicolumn{5}{|c|}{ Trying to Do Anything About Weight } \\
\hline Stay the Same Weight & 55 & 66 & 54 & 24 \\
\hline Lose Weight & 30 & 9 & 44 & 75 \\
\hline Gain Weight & 15 & 25 & 2 & 1 \\
\hline \multicolumn{5}{|c|}{ Tried to Lose Weight in Previous Year } \\
\hline Never & 54 & 75 & 35 & 14 \\
\hline Sometimes & 35 & 21 & 51 & 59 \\
\hline A Lot & 10 & 3 & 14 & 26 \\
\hline \multicolumn{5}{|l|}{ Girls } \\
\hline \multicolumn{5}{|l|}{ Weight Status Perception } \\
\hline About Right & 71 & 86 & 73 & 31 \\
\hline Too Thin & 5 & 8 & 0.4 & 1 \\
\hline Overweight & 23 & 6 & 27 & 68 \\
\hline \multicolumn{5}{|c|}{ Trying to Do Anything About Weight } \\
\hline Stay the Same Weight & 54 & 71 & 43 & 16 \\
\hline Lose Weight & 41 & 21 & 57 & 84 \\
\hline Gain Weight & 5 & 8 & 0.3 & 0 \\
\hline \multicolumn{5}{|c|}{ Tried to Lose Weight in Previous Year } \\
\hline Never & 41 & 57 & 28 & 8 \\
\hline Sometimes & 47 & 37 & 59 & 64 \\
\hline A Lot & 12 & 5 & 12 & 28 \\
\hline
\end{tabular}

NOTE: ${ }^{a} p$ values $<0.05$ for all comparisons across measured weight status category. 
Table 3. Multivariable linear regression models estimating associations of weight status perception and weight control intentions with nutrient intakes a among boys ages 10-15 years participating in the National Health and Nutrition Examination Survey 2005-2014 ( $\mathrm{n}=2493)$.

\begin{tabular}{|c|c|c|c|c|c|c|c|c|c|c|c|c|c|c|c|}
\hline & \multirow[b]{2}{*}{$\mathrm{n}$} & \multicolumn{2}{|r|}{ Calories } & \multicolumn{2}{|c|}{$\begin{array}{l}\text { Percent Calories from } \\
\text { Carbohydrate }\end{array}$} & \multicolumn{2}{|c|}{$\begin{array}{l}\text { Percent Calories from } \\
\text { Protein }\end{array}$} & \multicolumn{2}{|c|}{$\begin{array}{l}\text { Percent Calories from } \\
\text { Fat }\end{array}$} & \multicolumn{2}{|c|}{$\begin{array}{l}\text { Percent Calories from } \\
\text { Saturated Fat }\end{array}$} & \multicolumn{2}{|r|}{ Sugar } & \multicolumn{2}{|c|}{ Fiber } \\
\hline & & kcal & $95 \%$ CI & $\%$ & $95 \% \mathrm{CI}$ & $\%$ & $95 \% \mathrm{CI}$ & $\%$ & $95 \% \mathrm{CI}$ & $\%$ & $95 \% \mathrm{CI}$ & grams & $95 \% \mathrm{CI}$ & grams & $95 \% \mathrm{CI}$ \\
\hline \multicolumn{16}{|c|}{$\begin{array}{l}\text { Weight Status Perception } \\
\text { among Normal Weight }\end{array}$} \\
\hline About Right & 1201 & Ref & & Ref & & Ref & & Ref & & Ref & & Ref & & Ref & \\
\hline Too Thin & 201 & 153.82 & $-37.28,344.93$ & -0.99 & $-2.77,0.79$ & -0.04 & $-0.75,0.67$ & 0.82 & $-0.73,2.37$ & 0.57 & $-0.18,1.32$ & 1.30 & $-10.72,13.31$ & -0.98 & $-2.32,0.37$ \\
\hline Overweight & 31 & 32.41 & $-318.13,382.95$ & 0.24 & $-3.15,3.63$ & 0.30 & $-1.11,1.70$ & -0.45 & $-3.97,3.08$ & 0.19 & $-0.96,1.33$ & -6.33 & $-23.07,10.41$ & -0.13 & $-2.37,2.10$ \\
\hline \multicolumn{16}{|c|}{$\begin{array}{l}\text { Weight Status Perception } \\
\text { among Overweight/Obese }\end{array}$} \\
\hline About Right & 632 & Ref & & Ref & & Ref & & Ref & & Ref & & Ref & & Ref & \\
\hline Too Thin & 11 & -14.00 & $-480.29,452.30$ & 6.92 & $-2.68,16.53$ & -0.83 & $-2.80,1.15$ & -5.22 & $-14.48,4.05$ & -0.93 & $-4.32,2.47$ & 10.81 & $-12.06,33.68$ & 0.16 & $-3.45,3.77$ \\
\hline Overweight & 417 & 60.36 & $-83.00,204.72$ & -1.63 & $-3.52,0.26$ & 1.01 & $0.16,1.87^{\mathrm{b}}$ & 0.39 & $-0.99,1.78$ & 0.35 & $-0.35,1.04$ & -13.65 & $-23.06,-4.23^{\mathrm{b}}$ & -0.58 & $-1.60,0.43$ \\
\hline \multicolumn{16}{|c|}{$\begin{array}{l}\text { Trying to Do Anything About } \\
\text { Weight }\end{array}$} \\
\hline Stay the Same & 1237 & Ref & & Ref & & Ref & & Ref & & Ref & & Ref & & Ref & \\
\hline Lose Weight & 855 & -110.62 & $-228.55,7.30$ & 0.26 & $-0.95,1.48$ & 0.41 & $-0.26,1.07$ & -0.68 & $-1.52,0.16$ & -0.42 & $-0.52,0.43$ & -2.47 & $-8.18,3.25$ & -0.29 & $-1.10,0.51$ \\
\hline Gain Weight & 399 & 231.89 & $102.51,361.28^{\mathrm{b}}$ & 0.68 & $-0.99,2.34$ & -0.67 & $-1.33,-0.01^{b}$ & 0.02 & $-1.30,1.33$ & 0.17 & $-0.42,0.76$ & 8.25 & $-3.01,19.51$ & -0.56 & $-1.57,0.45$ \\
\hline \multicolumn{16}{|c|}{$\begin{array}{l}\text { Tried to Lose Weight in } \\
\text { Previous Year }\end{array}$} \\
\hline Never & 1273 & Ref & & Ref & & Ref & & Ref & & Ref & & Ref & & Ref & \\
\hline Sometimes & 937 & -117.65 & $-226.07,-9.23^{\mathrm{b}}$ & -0.31 & $-1.37,0.75$ & 0.64 & $0.11,1.18^{\mathrm{b}}$ & -0.29 & $-1.15,0.57$ & -0.05 & $-0.45,0.44$ & -0.31 & $-5.99,5.36$ & 0.32 & $-0.63,1.28$ \\
\hline A Lot & 281 & -188.34 & $-357.67,-19.01$ b & -0.03 & $-1.91,1.84$ & 1.48 & $0.41,2.55^{\mathrm{b}}$ & -1.41 & $-2.80,-0.02^{b}$ & -0.04 & $-0.73,0.64$ & -2.65 & $-10.45,5.15$ & -0.13 & $-1.48,1.22$ \\
\hline
\end{tabular}

Ref, Reference; ${ }^{a}$ All models are adjusted for body mass index percentile, race, age, poverty-to-income ratio, models for fiber and sugar are also adjusted for calories; ${ }^{\mathrm{b}} p<0.05$. 
Table 4. Multivariable linear regression models estimating associations of weight status perception and weight control intentions with nutrient intakes a among girls ages 10-15 years participating in the National Health and Nutrition Examination Survey 2005-2014 ( $\mathrm{n}=2447)$.

\begin{tabular}{|c|c|c|c|c|c|c|c|c|c|c|c|c|c|c|c|}
\hline \multirow[t]{2}{*}{ Categories } & \multirow[b]{2}{*}{$\mathrm{n}$} & \multicolumn{2}{|r|}{ Calories } & \multicolumn{2}{|c|}{$\begin{array}{l}\text { Percent Calories from } \\
\text { Carbohydrate }\end{array}$} & \multicolumn{2}{|c|}{$\begin{array}{c}\text { Percent Calories from } \\
\text { Protein }\end{array}$} & \multicolumn{2}{|c|}{$\begin{array}{l}\text { Percent Calories from } \\
\text { Fat }\end{array}$} & \multicolumn{2}{|c|}{$\begin{array}{l}\text { Percent Calories from } \\
\text { Saturated Fat }\end{array}$} & \multicolumn{2}{|r|}{ Sugar } & \multicolumn{2}{|c|}{ Fiber } \\
\hline & & kcal & $95 \%$ CI & $\%$ & $95 \%$ CI & $\%$ & $95 \%$ CI & $\%$ & $95 \%$ CI & $\%$ & $95 \%$ CI & grams & $95 \%$ CI & grams & $95 \%$ CI \\
\hline \multicolumn{16}{|c|}{$\begin{array}{l}\text { Weight Status Perception } \\
\text { among Normal Weight }\end{array}$} \\
\hline About Right & 1187 & Ref & & Ref & & Ref & & Ref & & Ref & & Ref & & Ref & \\
\hline Too Thin & 117 & 2.02 & $-188.99,193.04$ & -0.44 & $-3.04,2.16$ & 0.20 & $-0.81,1.21$ & 0.10 & $-2.07,2.27$ & 0.20 & $-0.72,1.12$ & -5.79 & $-16.04,4.46$ & 0.16 & $-1.06,1.38$ \\
\hline Overweight & 71 & -39.93 & $-377.28,297.42$ & 0.22 & $-2.70,3.14$ & 0.95 & $-1.04,2.94$ & -1.50 & $-3.31,0.31$ & -1.04 & $-2.24,-0.17^{b}$ & -2.49 & $-14.20,9.22$ & -0.29 & $-1.92,1.34$ \\
\hline \multicolumn{16}{|c|}{$\begin{array}{l}\text { Weight Status Perception } \\
\text { among Overweight/Obese c }\end{array}$} \\
\hline About Right & 524 & Ref & & Ref & & Ref & & Ref & & Ref & & Ref & & Ref & \\
\hline Overweight & 542 & -90.92 & $-242.58,63.74$ & -0.45 & $-2.54,1.64$ & -0.05 & $-0.96,0.86$ & 0.26 & $-1.33,1.85$ & -0.46 & $-1.14,0.23$ & -0.71 & $-8.20,6.78$ & 0.42 & $-0.65,1.49$ \\
\hline \multicolumn{16}{|c|}{$\begin{array}{l}\text { Trying to Do Anything About } \\
\text { Weight }\end{array}$} \\
\hline Stay the Same & 1235 & Ref & & Ref & & Ref & & Ref & & Ref & & Ref & & Ref & \\
\hline Lose Weight & 1079 & -56.86 & $-157.24,43.51$ & -0.47 & $-1.77,0.83$ & -0.06 & $-0.60,0.48$ & 0.37 & $-0.64,1.38$ & -0.24 & $-0.70,0.23$ & -2.41 & $-7.81,2.99$ & -0.13 & $-0.77,0.51$ \\
\hline Gain Weight & 133 & 9.25 & $-166.06,184.56$ & 0.05 & $-2.78,2.88$ & -0.33 & $-1.14,0.49$ & 0.23 & $-2.26,2.72$ & 0.04 & $-0.91,0.99$ & -3.80 & $-16.13,8.54$ & -0.50 & $-1.65,0.65$ \\
\hline \multicolumn{16}{|c|}{$\begin{array}{l}\text { Tried to Lose Weight in } \\
\text { Previous Year }\end{array}$} \\
\hline Never & 1023 & Ref & & Ref & & Ref & & Ref & & Ref & & Ref & & Ref & \\
\hline Sometimes & 1146 & -5.93 & $-107.06,95.20$ & 0.02 & $-1.40,1.44$ & -0.48 & $-1.06,0.09$ & 0.51 & $-0.52,1.54$ & 0.06 & $-0.39,0.51$ & 0.30 & $-4.86,5.47$ & 0.10 & $-0.53,0.72$ \\
\hline A Lot & 277 & -18.21 & $-132.72,96.29$ & 0.64 & $-1.37,2.64$ & 0.08 & $-1.03,1.20$ & -0.70 & $-2.28,0.87$ & -0.49 & $-1.21,0.23$ & 1.12 & $-6.41,8.65$ & 0.25 & $-0.55,1.05$ \\
\hline
\end{tabular}

Ref, Reference; ${ }^{\mathrm{a}}$ All models are adjusted for body mass index percentile, race, age, poverty-to-income ratio, models for fiber and sugar are also adjusted for calories; ${ }^{\mathrm{b}} p<0.05 ;{ }^{\mathrm{c}}$ There were only six girls who were overweight or obese and reported that they were too thin. 
Among boys, weight control intentions were associated with total calories, percent of calories from protein, and percent of calories from fat (Table 3). Compared to boys trying to stay the same weight, boys trying to gain weight consumed more calories $(231.89,95 \%$ CI: $102.51,361.28)$. Boys who reported trying to lose weight a lot in the previous year consumed fewer calories $(-188.34,95 \% \mathrm{CI}$ : $-357.67,-19.01)$ and percent calories from fat $(-1.41 \%, 95 \%$ CI: $-2.80,-0.02)$ and greater percent calories from protein $(1.48 \%, 95 \% \mathrm{CI}, 0.41,2.55)$ compared to those who never tried to lose weight. Weight control intentions were not associated with dietary intakes among girls (Table 4).

\section{Discussion}

Among a large, nationally representative sample of adolescents aged 10-15 years, perception of weight status as "about right" was highly prevalent among boys and girls, notably among those who were overweight or obese. Despite perceiving themselves as being at the right weight, many adolescents reported trying to lose or gain weight. Overall, weight status perception was not associated with dietary intakes in boys or girls, with the exceptions of lower consumption of sugar and percent calories from protein in boys with overweight or obesity who perceived themselves as overweight, and lower percent calories from saturated fat among girls with normal weight who perceived themselves as overweight. Weight control intentions were associated with dietary intakes in boys only. Compared to boys who never tried to lose weight, boys who reported trying to lose weight consumed fewer calories and percent of calories from fat and a greater percent of calories from protein.

In the current study, differences between boys and girls were observed for weight status perception and weight control intentions according to their measured weight status. Among boys with normal weight, $87 \%$ perceived themselves as just right, yet $25 \%$ reported trying to gain weight and $25 \%$ reported trying to lose weight in the previous year. Among girls with normal weight, $86 \%$ perceived themselves as just right, but $42 \%$ reported trying to lose weight in the previous year. This suggests that although adolescents may have a healthy weight, they are engaging in behaviors to change their weight status, especially weight loss. Similarly, among adolescents with overweight or obesity, the majority of girls and boys reported attempting to lose weight sometimes or a lot in the previous year. These observations are concerning, because adolescents, particularly within the age range of 10-15 years, are growing and undergoing other physical changes with high nutrient demands [16]. Given that unhealthy weight management strategies may be used by adolescents, it is important that adolescents are educated about healthy dietary and physical activity practices during this time [9,21,22].

In general, weight status perception was not associated with dietary intakes, except for overweight boys who perceived themselves as overweight, who consumed less sugar and more protein, and girls with normal weight who perceived themselves as overweight, who consumed less saturated fat. These findings are consistent with those from three other studies using nationally representative samples of adolescents. In a previous analysis of adolescents ages 12-18 years in NHANES III, weight status perception was not associated with intakes of energy, macronutrients, micronutrients, or low energy-dense foods, or serum concentrations of vitamins and carotenoids. The only exceptions were that boys who perceived themselves as overweight consumed less saturated fat $(<10 \%$ of energy intake) and girls who perceived themselves as overweight consumed less calcium, compared to their respective counterparts who perceived themselves as being the right weight [13]. Among 9th-12th graders participating in the U.S. Youth Risk Behavior Surveillance Survey (YRBSS, 2001-2009) and among eighth graders, consumption of food groups, including fruits, vegetables, and soft drinks, did not differ by weight status perception $[5,14]$. However, perception of being overweight was associated with higher calorie, fat, and protein intakes among Chinese children and adolescents ages 6-11 years, although there were no associations observed for those ages 12-17 years [15]. Though all of these studies were cross-sectional, their results, taken collectively, suggest that weight status perception alone may not be strongly associated with dietary intakes.

Studies that examined associations of weight control intentions and dietary intakes in adolescents are limited. In the analysis of YRBSS participants, weight loss intentions (defined as trying to lose 
weight, through diet and/or exercise) were not associated with fruit/vegetable or soft drink intakes [14]. Similarly, among 8th graders, there were no differences in fruit, vegetable, soda, or fast food intake among those trying to lose weight compared to those not doing anything, but higher soda and fast food intakes were reported by those trying to gain weight. In the current study, intentions to change weight status (gain or lose weight) were associated with intakes of calories, fat, and protein among boys only. These findings contrast with those from a longitudinal analysis of the Project Eating Among Teens (EAT) study, which evaluated the relationship of healthful and unhealthful weight control behaviors with dietary intakes [23]. Among girls, persistent use of unhealthful weight control behaviors (over a 5-year period) was associated with less frequent meal consumption (e.g., breakfast), lower calorie intakes, and lower intakes of healthy dietary components, including fiber, calcium, iron, vegetables, and whole grains. In boys, persistent use of unhealthy weight control behaviors was only associated with less frequent meal consumption [23]. Discrepancies across studies are likely due to a range of factors, including study design, population characteristics, and data collection methods. The findings from the Project EAT study highlight the need for longitudinal studies of adolescents that follow them through the transitional period from late childhood/early adolescence to late adolescence/early adulthood.

Strengths of this study include the large sample size and nationally representative, ethnically-diverse population. The age range of 10-15 years allowed for focus on younger adolescents, which is understudied in the literature. Weight and height were measured by trained health professionals, which eliminates potential bias from self-reported values. Additionally, dietary intakes were represented as major nutrient intakes, which are reflective of food groups. For example, higher fiber intakes are generally associated with intakes of fruits, vegetables, and whole grains, while higher sugar intakes are generally associated with high energy-dense foods, such as confectionaries and sugar-sweetened beverages [24]. Analyses were limited by the cross-sectional design and method of dietary assessment; participants completed up to two 24-h recalls, which may not be reflective of usual diet. Weight perception and control intentions were based on three questions with limited response choices, which may not adequately discern them.

\section{Conclusions}

In this study, most 10-15 year olds perceived their weight as "about right" but still reported trying to change their weight, which was associated with some dietary intakes. These findings add to the current literature regarding how weight perception and weight control intentions may relate to dietary intakes in young adolescents. Future research should include longitudinal data collection encompassing a wider age range within adolescence, comprehensive dietary assessments, and detailed questions regarding weight control and eating practices.

Author Contributions: A.L.D. contributed to the conception of the work and writing and revising of the manuscript. A.M. conducted statistical analyses and contributed to the writing of the manuscript. J.L. contributed to the statistical analyses and revising of the manuscript. N.P. contributed to the revising of the manuscript.

Funding: This research did not receive any specific grant from funding agencies in the public, commercial, or not-for-profit sectors.

Conflicts of Interest: No competing financial interests exist.

\section{Abbreviations}

$\begin{array}{ll}\text { NHANES } & \text { National Health and Nutrition Examination Surveys } \\ \text { BMI } & \text { body mass index }\end{array}$

\section{References}

1. Brener, N.D.; Eaton, D.K.; Lowry, R.; McManus, T. The Association between weight Perception and BMI among high school students. Obes. Res. 2004, 12, 1866-1874. [CrossRef] [PubMed] 
2. Sarafrazi, N.; Hughes, J.P.; Borrud, L.; Burt, V.; Paulose-Ram, R. Perception of weight status in U.S. Children and adolescents aged 8-15 years, 2005-2012. NCHS Data Brief 2014, 158, 1-8.

3. Viner, R.M.; Haines, M.M.; Taylor, S.J.C.; Head, J.; Booy, R.; Stansfeld, S. Body mass, weight control behaviours, weight perception and emotional well being in a multiethnic sample of early adolescents. Int. J. Obes. 2006, 30, 1514-1521. [CrossRef] [PubMed]

4. Strauss, R.S. Self-reported weight status and dieting in a cross-sectional sample of young adolescents: National Health and Nutrition Examination Survey III. Arch. Pediatr. Adolesc. Med. 1999, 153, 741-748. [CrossRef] [PubMed]

5. Datar, A.; Chung, P.J. Accuracy of weight perceptions in a nationally representative cohort of US 8th grade adolescents. Acad. Pediatr. 2016, 16, 267-274. [CrossRef] [PubMed]

6. Cai, L.; Zhang, T.; Ma, J.; Ma, L.; Jing, J.; Chen, Y. Self-perception of weight status and its association with weight-related knowledge, attitudes, and behaviors among Chinese children in Guangzhou. J. Epidemiol. 2017, 27, 338-345. [CrossRef]

7. Zullig, K.; Ubbes, V.; Pyle, J.; Valois, R.F. Self-reported weight perceptions, dieting behavior, and breakfast eating among high school adolescents. J. Sch. Health 2006, 76, 87-93. [CrossRef]

8. Demissie, Z.; Lowry, R.; Eaton, D.K.; Nihiser, A.J. Trends in weight management goals and behaviors among 9th-12th grade students: United States, 1999-2009. Matern. Child. Health J. 2014, 19, 74-83. [CrossRef]

9. Martin, B.C.; Dalton, W.T.; Williams, S.L.; Slawson, D.L.; Dunn, M.S.; Johns-Wommack, R. Weight status misperception as related to selected health risk behaviors among middle school students. J. Sch. Health 2014, 84, 116-123. [CrossRef]

10. Chung, A.E.; Perrin, E.M.; Skinner, A.C. Accuracy of child and adolescent weight perceptions and their relationship to dieting and exercise behaviors: NHANES. Academic pediatrics 2014, 13, 371-378. [CrossRef]

11. Golden, N.H.; Schneider, M.; Wood, C. Preventing Obesity and Eating Disorders in Adolescents. Pediatrics 2016, 138, e20161649. [CrossRef]

12. Lebow, J.; Sim, L.A.; Kransdorf, L.N. Prevalence of a history of overweight and obesity in adolescents with restrictive eating disorders. J. Adolesc. Health 2015, 56, 19-24. [CrossRef]

13. Kant, A.K. Association of self-perceived body weight status with dietary reporting by U.S. Teens*. Obes. Res. 2002, 10, 1259-1269. [CrossRef]

14. Fan, M.; Jin, Y. The effects of weight perception on adolescents' weight-loss intentions and behaviors: Evidence from the Youth Risk Behavior Surveillance Survey. Int J Environ Res Public Health 2015, 12, 14640-14668. [CrossRef] [PubMed]

15. Niu, J.; Seo, D.C.; Lohrmann, D.K. Weight perception and dietary intake among Chinese youth, 2004-2009. Int. J. Behav. Med. 2014, 21, 691-699. [CrossRef] [PubMed]

16. Stang, J.; Story, M. (Eds.) Adolescent Growth and Development. In Guidelines for Adolescent Nutrition Services; University of Minnesota: Minneapolis, MN, USA, 2005; pp. 1-8.

17. NHANES. About the National Health and Nutrition Examination Survey. Available online: https:/ /www. cdc.gov/nchs/nhanes/about_nhanes.htm (accessed on 1 May 2018).

18. NHANES. NCHS Research Ethics Review Board Approval. Available online: https:/ /www.cdc.gov/nchs / nhanes/irba98.htm (accessed on 1 May 2018).

19. Centers for Disease Control and Prevention (CDC). National Health and Nutrition Examination Survey Data. Hyattsville, MD: U.S. Department of Health and Human Services, Centers for Disease Control and Prevention; National Center for Health Statistics (NCHS). Available online: http:/ /www.cdc.gov/nchs. nhanes.htm (accessed on 18 March 2018).

20. Ogden, C.L.; Flegal, K.M. Changes in terminology for childhood overweight and obesity. Natl. Health Stat. Rep. 2010, 25, 1-5.

21. Vander Wal, J.S. Unhealthy weight control behaviors among adolescents. J. Health Psychol. 2012, 17, 110-120. [CrossRef] [PubMed]

22. Neumark-Sztainer, D.; Wall, M.M.; Story, M.; Perry, C.L. Correlates of unhealthy weight-control behaviors among adolescents: Implications for prevention programs. Health Pscyhol. 2003, 22, 88-98. [CrossRef] 
23. Larson, N.I.; Neumark-Sztainer, D.; Story, M. Weight control behaviors and dietary intake among adolescents and young adults: Longitudinal findings from Project EAT. J. Am. Diet. Assoc. 2009, 109, 1869-1877. [CrossRef] [PubMed]

24. Farris, R.P.; Nicklas, T.A.; Myers, L.; Berenson, G.S. Nutrient intake and food group consumption of 10-Year-Olds by sugar intake level: The Bogalusa Heart Study. J. Am. Coll. Nutr. 1998, 17, 579-585. [CrossRef] [PubMed]

(c)

(C) 2019 by the authors. Licensee MDPI, Basel, Switzerland. This article is an open access article distributed under the terms and conditions of the Creative Commons Attribution (CC BY) license (http://creativecommons.org/licenses/by/4.0/). 